\title{
O Sínodo para a Amazônia: um sínodo marcado pela escuta e pela alteridade
}

\author{
The Synod of the Amazon: a synod signed by
}

listening and otherness

MoAB CÉSAR CARVALho COSTA ${ }^{a}$

\section{Resumo}

Este artigo representa uma contribuição direta dos trabalhos sinodais, desde o Círculo de Língua Portuguesa "A" em que o autor participou, como primeiro pentecostal presente num Sínodo, na qualidade de delegado fraterno. Donde o estilo de reflexão aberta, com enfoques diferentes e convergentes, tecida há poucas horas do encerramento dos trabalhos sinodais. De início, o autor retoma Michel De Certeau com sua proposta sobre a alteridade e o diálogo, no intento de superar atitudes colonizadores face às culturas, tão diversas. Do pensador Certeau ao papa Francisco dá-se uma longa conexão entre jesuítas, com a peculiaridade do segundo como o primeiro pontífice latino-americano, na história da Igreja Católica. Fato que o autor destaca como "conditio sine qua non" para a proposta, método, abordagem e resultados característicos do Sínodo para a Amazônia. Considerando a convicção ecumênica do Papa (em sintonia com o Concílio Vaticano II) e a presença pentecostal no território amazônico, o autor respondeu ao convite de participar do Sínodo como delegado fraterno pentecostal, enfatizando a teologia da amizade como disposição de encontro e diálogo com a Igreja Católica.

Palavras-chave: Sínodo para a Amazônia. Igreja Pentecostal. Teologia da amizade. Papa Francisco.

\footnotetext{
a Universidade Estadual da Região Tocantina do Maranhão (UEMASUL), Imperatriz, MA, Brasil. Doutor em História, e-mail: moabcesar@yahoo.com.br
} 


\title{
Abstract
}

This article represents a direct contribution of the Synodal works, from the Portuguese Language Circle " $A$ " in which the author participated, as the first Pentecostal present in a Synod, as a fraternal delegate. Hence the style of open reflection, with different and convergent approaches, woven a few hours after the closing of the synodal works. At first, the author takes up Michel De Certeau with his proposal on otherness and dialogue, in order to overcome colonizing attitudes in the face of Cultures. From thinker Certeau to Pope Francis there is a long connection between the two Jesuits, with the peculiarity of the second as the first Latin American pontiff in the history of the Catholic Church. This fact is highlighted by the author as "conditio sine qua non" for the proposal, method, approach and results characteristic of the Amazon Synod. Considering the Pope's ecumenical conviction (in line with the Second Vatican Council) and the Pentecostal presence in the Amazon territory, the author responded to the Catholic invitation to participate in the Synod as a Pentecostal fraternal delegate, emphasizing the theology of friendship as a disposition to meet and dialogue with the Catholic Church.

Keywords: Amazon Synod. Pentecostal Church. Theology of friendship. Pope Francis.

\begin{abstract}
Américo Vespúcio, o descobridor, vem do mar. De pé, vestido, encouraçado, cruzado, trazendo as armas europeias do sentido e tendo por detrás dele os navios que trarão para o Ocidente os tesouros de um paraíso. Diante dele a América Índia, mulher estendida, nua, presença não nomeada da diferença, corpo que desperta num espaço de vegetações e animais exóticos. Cena inaugural. Após um momento de espanto nesse limiar marcado por uma colunata de árvores, o conquistador irá escrever o corpo do outro e nele traçar a sua própria história. Fará dele o corpo historiado - o brasão - de seus trabalhos e de seus fantasmas. Isso será a América Latina (DE CERTEAU, 2011, p. 6)
\end{abstract}

O texto acima, é a descrição feita por Michel de Certeau da alegoria desenhada por Jan Van der Stract em 1619. Ele a denomina de escrita conquistadora, utilizando como exemplo, para demostrar que a partir da literatura de viajantes, a América Latina ganhou contornos e identidades impostas pelos colonizadores. Essa identidade plasmada, dominadora é totalmente indiferente àquilo que descreve (não ouve e nem quer ouvir o que o outro quer dizer sobre si mesmo). Cada uma dessas identidades, impostas, servirá aos interesses dos diversos segmentos da cultura ocidental que cruzaram o Atlântico para dominar, estabelecer e explorar. Explorar até exaurir.

No bojo desse processo de colonização, a Igreja Católica atuou como legitimadora das ações conquistadoras em nome de Deus e contra todos os demônios adorados pelos povos indígenas da América, bem como dos africanos 
escravizados e aqui introduzidos. A igreja, ao demonizar a religião dos povos originários e dos africanos, empreendeu suas cruzadas colonialistas em nome da fé e do cristianismo. Agiu com braço forte, impôs a ferro e fogo a catequização, condenando todas as práticas, crenças, ritos e tradições ${ }^{2}$. Por consequência, durante séculos agiu sem exercer a escuta e muito menos a alteridade. A alteridade foi um conceito inexistente na mentalidade do colonizador.

Numa perspectiva contrária a escrita conquistadora, Michel de Certeau orienta a escuta, a alteridade e a necessidade de aceitar o outro como ele é, como ele se identifica, como ele compreende a si mesmo, bem como ele interpreta seus próprios valores, cosmovisão e cultura. Essa postura diante do outro de Michel de Certeau, a da ESCUTA, orientou o Sínodo para a Amazônia assim com o termo AGGIORNAMENTO orientou e balizou o Concílio Vaticano II.

Após a leitura da encíclica Laudato Si e do Instrumentum Laboris, documentos referência para o Sínodo para a Amazônia, na primeira oportunidade que tive, perguntei ao Papa Francisco se ele era leitor dos textos do jesuíta Michel de Certeau. Ele me respondeu que sim e que o considerava como o mais importante teólogo e filósofo do século XX.

A escuta, chave para o desenvolvimento do Sínodo, ocorreu antes, com o objetivo de elaborar o Instrumentum Laboris e durante o Sínodo. A presença de indígenas, mulheres consagradas e leigas, militantes de causas sociais, especialistas na área ecológica e líderes religiosos de outras denominações cristãs (delegados fraternos), além, claro, dos bispos, cardeais e representantes de diversos setores da Igreja Católica, bem como a presença constante do Papa Francisco, promoveram um evento sem precedente na história da Igreja.

\footnotetext{
${ }^{2}$ No caso do Brasil, que recebeu o maior contingente de africanos escravizados, as relações geradas entre estes três grupos: os dos colonizadores católicos, dos africanos aqui introduzidos e dos povos indígenas produziram um amálgama simbólico carregado de hibridismo, que de certa forma atuou como tática de sobrevivências cultural dos povos colonizados e escravizados. Não é sem razão que a matriz religiosa brasileira é rica em suas crenças, ritos e símbolos. E nessa riqueza encontramos pessoas que transitam com muita facilidade em todas essas tradições religiosas.
} 


\section{Conditio Sine Qua Non}

Há uma questão fundamental que deve ser considerada neste ponto: o que permitiu que um evento dessa natureza, com essa composição e com temáticas que priorizam e dão voz, além das questões ecológicas, aos indígenas, às comunidades estabelecidas na Amazônia, aos pobres da terra e explorados nas cidades, pudesse ser realizado pela Igreja Católica, e em especial na cidade do Vaticano, lócus norteador e referência simbólica do universo católico?

A resposta que apresento é simples. Só foi possível em virtude de o Papa ser, pela primeira vez na história, um latino-americano. Alguém que sabe o que é ser colonizado e explorado, que conhece o clamor do povo cuja voz nunca antes havia sido ouvida com tanta atenção. Embora, o pontificado de João Paulo II tenha dado alguma atenção neste sentido, somente o Papa Francisco conhecia o sentimento de não ser ouvido, ignorado, invisibilizado e explorando de todas as formas possíveis.

Partindo dessa perspectiva, vou traçar, a partir de então, minhas impressões do que vi, ouvi e falei no Sínodo para a Amazônia, na qualidade de Delegado Fraterno, por ser membro de uma igreja pentecostal no Brasil, as Assembleias de Deus.

\section{O que faz um pentecostal no Sínodo para a Amazônia?}

No Sínodo dos Bispos da Região Pan-Amazônica (6 a 27 de outubro de 2019), de acordo com uma tradição inaugurada no Concílio Vaticano II, um grupo de delegados fraternos de outras comunidades cristãs participou. Os delegados, originários do Brasil, Colômbia e Peru, quase todos exercem sua atividade eclesial na região Pan-Amazônica. Todos se chamam evangélicos ("evangélicos"). Muitos são pastores: um luterano, dois anglicanos (um ministro e um leigo), um presbiteriano, um batista e um pastor das Assembléias de Deus (pela primeira vez um delegado pentecostal participou do Sínodo dos Bispos) (PCPCU 2019, News) (grifos nossos).

O texto acima, publicado pelo Pontifício Conselho para a Promoção da Unidade Cristã, destaca que "pela primeira vez um delegado pentecostal participou do Sínodo dos Bispos". Os pentecostais brasileiros têm crescido de forma assustadora aos olhos da Igreja Católica. Implantado em 1910 e 1911, respectivamente, por um missionário italiano, Luigi Francescon, fundador da 
Congregação Cristã do Brasil — CCB e pelos missionários suecos, Daniel Berg e Gunnar Vingren, fundadores das Igrejas Evangélicas Assembleia de Deus no Brasil, na cidade de Belém do Pará, no coração da Amazônia.

Como exemplo desse crescimento, vou apresentar uma tabela com os dados estatístico dos censos do IBGE de 1950 a 2010 na cidade de Imperatriz (MA), localizada no Sudoeste do Estado, também conhecida como portal da Amazônia Oriental. Nesta é possível observar a redução do percentual dos que se declaram católicos, a estagnação dos protestantes e o crescimento acelerado dos pentecostais. As Assembleias de Deus vão se firmar como a representante maior do pentecostalismo em Imperatriz (MA) e seu crescimento será proporcional ao crescimento e desenvolvimento da cidade.

Tabela 1 - População x Religião ${ }^{3}$ nos censos do IBGE de 1950 a 2010 na cidade de Imperatriz, MA

\begin{tabular}{|c|c|c|c|c|c|c|c|c|c|}
\hline \multirow[t]{2}{*}{ Censo } & \multirow{2}{*}{$\begin{array}{l}\text { População } \\
\text { Total }\end{array}$} & \multicolumn{2}{|l|}{ Católicos } & \multicolumn{2}{|c|}{ Protestantes } & \multicolumn{2}{|c|}{ Pentecostais } & \multicolumn{2}{|c|}{ Sem religião } \\
\hline & & Quantidade & $\%$ & Quantidade & $\%$ & Quantidade & $\%$ & Quanti. & $\%$ \\
\hline 1950 & 14.064 & 13.631 & $96,9 \%$ & 195 & $1,3 \%$ & $\mathrm{NI}$ & - & $\mathrm{NI}$ & - \\
\hline 1960 & 39.169 & 37.223 & $95,05 \%$ & 1.712 & $4,3 \%$ & $\mathrm{NI}$ & - & $\mathrm{NI}$ & - \\
\hline 1970 & 80.827 & 73.859 & $91,3 \%$ & 6.275 & $7,7 \%$ & $\mathrm{NI}$ & - & $\mathrm{NI}$ & - \\
\hline 1980 & 220.095 & 196.518 & $89,2 \%$ & 6.047 & $2,7 \%$ & 13.240 & $6,0 \%$ & $\mathrm{NI}$ & - \\
\hline 1991 & 276.501 & 232.331 & $84,0 \%$ & 7.938 & $2,8 \%$ & 23.517 & $8,5 \%$ & 8.797 & $3,18 \%$ \\
\hline 2000 & 230.566 & 162.053 & $70,2 \%$ & 11.592 & $5,0 \%$ & 36.386 & $15,7 \%$ & 15.169 & $6,58 \%$ \\
\hline 2010 & 247.505 & 138.785 & $56,04 \%$ & 15.080 & $6,09 \%$ & 53.053 & $21,72 \%$ & 20.898 & $8,44 \%$ \\
\hline
\end{tabular}

Fonte: COSTA (2019b, p. 172).

Os dados sobre a relação entre população e religião na cidade de Imperatriz refletem a realidade do campo religioso brasileiro. Os índices de queda dos que se declaram católicos nos censos de 1991 a 2010 são aproximadamente de 14\%. Se mantida essa média, o censo de 2020 vai apresentar um quadro onde os que se declaram católicos terão percentuais abaixo de 50\%. O Brasil já não é mais um país

\footnotetext{
${ }^{3}$ Os dados se referem apenas aos católicos, protestantes, pentecostais e sem religião. Não são apresentados os demais segmentos em virtude do foco de nossa análise.
} 
católico, mas um país "evangélico" e com forte presença dos que se declaram sem religião.

A presença de um evangélico pentecostal, e da Assembleia de Deus, no Sínodo para a Amazônia pode ter muitos significados, e isso vai depender de quem observa ou melhor, do lugar social de quem observa. Na minha perspectiva, significa um reconhecimento da importância e força desse segmento no Brasil, de sua capacidade de articulação e da possibilidade de juntos, em defesa de causas comuns, que vão além das questões religiosas, mas, que refletem aquilo que é conhecido como fraternidade universal, promoverem ações em defesa da vida dos menos favorecidos, dos injustiçados e de uma Ecologia Integral. Como disse o Papa Francisco, “tudo está interligado". Essa talvez não seja, ainda, uma perspectiva institucional oficial. Não existe no segmento pentecostal uma clareza dos benefícios do diálogo, e por essa razão há muita dificuldade de naturalizar esse tipo de ação.

Nesse sentido, a presença de um pentecostal no Sínodo é um primeiro passo para um diálogo mais respeitos entre os vários segmentos do cristianismo brasileiro. No campo religioso protestante pentecostal não existe unidade teológica. Há uma diversidade incontável de perspectivas teológicas que vão desde questões simples, como os usos e costumes, até o exclusivismo soteriológico. No entanto, há um respeito entre eles. Esse mesmo respeito, na minha opinião, pode existir em relação aos católicos. E nessa perspectiva, apresentei algumas propostas no Sínodo. É o que vamos ver no próximo tópico.

\section{A Teologia da Amizade com chave para o diálogo ecumênico e inter-religioso}

A dinâmica adotada para a realização do Sínodo foi algo totalmente novo para mim. A sala sinodal foi o palco das reuniões de assembleia geral. Nela cada participante tinha quatro minutos para falar. Não havia intervenções nem debate nestas reuniões. Ouvia-se em silêncio; depois de ouvir quatro palestrantes, iniciava-se um período de reflexão individual por quatro minutos. Assim ocorreu durante todo o evento. Na última hora do período vespertino era permitido fazer falas livres, de até três minutos, sobre o que se havia ouvido durante o dia. Nessas ocasiões o Papa Francisco por duas vezes utilizou a palavra. 
O exercício da escuta e da reflexão foi fundamental para evitar os excessos e os julgamento precipitados. Houve muitas falas distintas; a maioria refletindo as considerações do Instrumentum Laboris (texto base dos trabalhos sinodais); outras, principalmente dos representantes dos povos indígenas, traziam as marcas da dor e da angústia que sentiam no cotidiano de lutas, de exploração e de invisibilidade. Essa é uma das grandes marcas do Sínodo para a Amazônia. A Igreja Católica, protagonista de tantas ações colonialistas no passado, reconhecendo seus muitos erros, coloca-se diante daqueles a quem provocou sofrimento e dor, para ouvi-los. Essa escuta, respeitosa, humilde, carregada de alteridade e de Interculturalidade anuncia novos cominhos para a igreja. Embora, todas as questões tivessem como locus a Amazônia, o que for posto em prática vai refletir em todo o universo católico. Abaixo coloco o texto de minha fala na Assembleia Geral do Sínodo. De acordo com o regulamento do Sínodo, antes de iniciar era preciso declarar o número do Instrumentum Laboris que embasaria a fala (REGULAMENTO, 2019, p. 15):

Instrumentum Laboris nº 136 - 139

Saúdo vossa santidade, o Papa Francisco, e em seu nome todos os irmãos e irmãs presentes neste sínodo.

Que a paz do nosso Senhor Jesus Cristo promova a unidade e o amor.

Trago uma saudação das Igrejas evangélicas Assembleia de Deus no Brasil, em especial, das localizadas na Região da Amazônia oriental.

Trago uma saudação da Rede Latino-americana de Estudos Pentecostais - RELEP, formada por pesquisadores pentecostais e católicos de 15 países da América Latina.

No decurso da história do cristianismo, as questões teológicas promoveram o distanciamento entre pessoas e instituições que o representam

No entanto, acima dessas questões existem causas que devem unir toda a cristandade, não apenas ela, mas, toda a humanidade, independentemente de suas tradições religiosas e de suas perspectivas culturais.

A casa comum de toda a humanidade, a terra, é uma delas. Preservar sua flora, sua fauna, seus rios, promover o equilíbrio ambiental, numa perspectiva da Ecologia Integral (uma vez que tudo está interligado), é um "conditio sine qua non" para o futuro da humanidade. E a preservação da Amazônia, a defesa dos povos originários que nela habitam, bem como das comunidades lá estabelecidas, são essenciais neste momento. Felicitamos a Santa Sé por esta iniciativa, por levantar esta bandeira.

O ímpeto destruidor do capitalismo de consumo e da cultura da obsolescência programada e do descartável, os avanços destruidores das fronteiras agrícolas, a industrialização da exploração mineral e da produção de energia na Amazônia, colocam em risco o futuro da humanidade. É preciso unir forças em sua defesa.

Em algumas regiões no Brasil, católicos e pentecostais uniram forças para disputar pleitos políticos, como aconteceu na cidade de Bom Jesus das Selvas, no estado do Maranhão. 
Quanto mais agora, numa causa comum, a defesa do planeta, vejo a possibilidade de uma união maior, mais excelente. E nesse sentido, tornar-se necessário o diálogo, não apenas no nível que aqui acontece, mas ao rés do chão.

Encerro minha fala fazendo uma sugestão: apenas na convenção das Igrejas Assembleias de Deus que pertenço, existem mais de 2.000 pastores, a maioria na região amazônica brasileira. Provoquem o diálogo, visitem nossas igrejas, falem com nossos pastores, tomem um café juntos, e tenho certeza, que por esta causa, a casa comum, muitos irão unir forças. A Teologia da Amizade é a chave para o diálogo ecumênico e inter-religiosos.

$\mathrm{O}$ amigo, a amiga respeita, cuida e protege.

E como diz o salmista, "quão bom e quão agradável é que os irmãos vivam em união". Muito obrigado! (COSTA, 2019c)

Se nas assembleias gerais não havia debates, réplicas e discursos sobre os temas apresentados, uma vez que aquele espaço era de escuta e reflexão, os debates ocorreram de forma muito profícua nos Círculos Menores.

Foram organizados 12 Círculos Menores, com o número de participantes que variavam entre 23 e 28 membros, divididos por idiomas. 5 de fala espanhola, 2 de fala italiana, 1 de faça inglês/francês e 4 de fala portuguesa. Os Círculos Menores eram compostos por bispos (padres sinodais, com direito a voto), especialistas, auditores, delegado Fraterno (1 por grupo) e assistentes. Nem todos os grupos contavam com a presença de delegados fraterno. Havia um moderador e um relator, escolhido entre os padres sinodais.

Cada círculo optou por uma metodologia de trabalho própria, de sorte que no final teriam que apresentar uma síntese dos debates organizados por assuntos. Essa síntese seria lida na Assembleia Geral e faria parte do documento final. Fui designado para o Círculo Português "A". Os tópicos tratados neste círculo foram os seguintes: 1. Igreja Sinodal: novos caminhos para a missão; 2. Ministérios ordenados instituídos no que tange a celebração da Palavra de Deus e Sacramentos, em especial a Eucaristia; 3. Uma igreja com rosto amazônico e missionário para os leigos, religiosos, diáconos, padres, bispos (uma formação inculturada na Amazônia); 4. A Igreja na Amazônia é formada por muitas comunidades; 5. A migração e seus efeitos; 6 . A violência (narcotráfico e narconegócio, extermínio de população juvenil, tráfico de pessoas, superlotação de presídios); 7. Os povos originários e a comunidades estabelecidas na Amazônia; 8 . O diálogo ecumênico e inter-religioso; 9. A Ecologia Integral e a cosmovisões indígenas; 10. A espiritualidade e a sabedoria dos ancestrais; 11. A Educação Integral; 12. A opção pelos pobres; 13. 
Os mártires da Amazônia (missionários e militantes); 14. A comunicação em tempos de Fake News.

O Círculo refletiu as várias falas que ocorreram nas assembleias gerais. Nossa contribuição maior foi no tema relativo ao diálogo ecumênico e inter-religioso. Embora, nos debates relacionados a Ecologia Integral tenha apresentado algumas experiências como alternativa para amenizar os impactos ambientais. Um deles foi sobre a recente implantação de um curso Engenharia Agronômica da Universidade Estadual da Região Tocantina, Campus do Estreito, voltada para a agricultura familiar. Geralmente os cursos de Agronomia privilegiam os grandes projetos agrícolas, bem como o fomento para a expansão das fronteiras agrícolas.

No campo do diálogo ecumênico e inter-religioso, apresentei a Teologia da Amizade como a chave para o diálogo, para o fortalecimento da Fraternidade Universal e para a unidade nas lutas que são comuns a todos os seres humanos. Reforcei a sugestão que fiz na assembleia geral para que os padres e bispos provocassem o diálogo, visitassem as igrejas, falassem com os pastores, tomassem um cafezinho juntos. Assim como sugeri, também apliquei essa mesma estratégia durante o Sínodo. Provoquei muitos contatos, dialoguei com quase todos os bispos e cardeais presentes, com todos os delegados fraternos, com especialistas e lideranças indígenas, troquei contatos de e-mail e telefônicos.

Esses contatos me enriqueceram de forma muito especial. Por várias vezes provoquei o diálogo com o Papa Francisco, e neles falamos sobre a perspectiva filosófica e teológica de Michel De Certeau, sobre a importância das mulheres nas igrejas pentecostais e o quanto era significativo um Sínodo daquela natureza e com aquelas presenças, antes não nominadas e invisibilizadas, mas agora ouvidas e respeitadas.

A teologia da Amizade favorece o diálogo, como dito antes, mas não elimina as diferenças teológicas, doutrinárias e institucionais. Esse não é o objetivo. $\mathrm{O}$ objetivo desta é favorecer o convívio respeitoso e o bem-estar entre os que comungam de perspectivas religiosas iguais e diferentes, tanto na mesma tradição como em tradições religiosas diferentes. O mundo é outro, não há mais um bloco monolítico e monopolista do poder simbólico, é preciso entender e garantir a liberdade religiosa do outro para que a nossa seja respeitada. Essa é uma herança da Reforma Protestante, nem sempre respeitada, a liberdade religiosa. 
Vejamos abaixo, como ficou minha propositura para iniciar uma etapa mais significativa do diálogo católico-pentecostal.

Na Amazônia gozamos de uma biodiversidade ecológica, intercultural, religiosa e espiritual. Sabemos que o diálogo é a ponte para a construção da paz e do "bem viver". Diante das diferenças propomos um diálogo ecumênico e inter-religioso. "não haverá paz no mundo se não houver paz entre as religiões" (Hans Kung). Propomos dois colóquios entre os teólogos da RELEP4 (Rede Latino-americana de Estudos Pentecostais) e os teólogos católicos. Um na Amazônia e outro em Roma. Esses dois encontros, como primeiro passo, serão fundamentais para o aprofundamento do diálogo e unidade em relação à questões comuns: Cristo Jesus, fundamento de nossas fé, bem como a defesa da "Casa Comum", da Ecologia Integral, da vida e da luta pelas garantias dos direitos humanos, na floresta, no campo e na cidade (CIRCOLO PORTOGHESE "A", p. 2-3) (grifos originais).

\section{Considerações finais}

Há muitos outros temas que poderiam ser tratados aqui, mas os limites do texto impedem, especialmente aqueles relacionados à consagração de mulheres no ministério ordenado, que ainda é um tema polêmico, tanto na Igreja Católica quanto nas igrejas do pentecostalismo clássico, como as Assembleias de Deus. Embora, em algumas convenções elas possam ser consagradas a pastoras. Essas consagrações ainda não refletem o verdadeiro valor a ser reconhecido, uma vez que, mesmo consagradas, elas geralmente são esposas de pastores, e não podem, ainda, pastorear e dirigir igrejas. É uma forma intermediária de um processo que levará tempo para se naturalizar entre as igrejas pentecostais clássicas.

Essa foi uma experiência sem precedente em minha vida. Participar de Sínodo dos Bispos da Igreja Católica, tendo a presença em quase todas as sessões do Papa Francisco, ao lado de convidados especiais que representaram os povos indígenas, as comunidades tradicionais da Amazônia, os militantes das causas sociais e ecológicas. Essa proximidade criou vínculos, me fez refletir que é possível mudar, a partir de dentro, ouvindo os que estão de fora, uma realidade que por muito tempo plasmou a história da religião católica no mundo.

Se é possível mudar o mundo eu não sei, mas sei que eu posso mudar a mim mesmo e agir na perspectiva de que tudo está interligado.

\footnotetext{
${ }^{4}$ Maiores informações sobre a RELEP acessar o link www.relep.org.br.
} 


\section{Referências}

ASSEMBLEIA ESPECIAL DO SÍNODO DOS BISPOS. Amazônia: novos caminhos para a Igreja e para uma ecologia integral - Instrumentum Laboris para a Assembleia Especial do Sínodo dos Bispos para a Região Pan-amazônica. Brasília: Edições CNBB, 2019.

COSTA, M. C. C. Delegati fraterni al Sinodo dei Vescovi per la Regione Pan-amazzonica. 28 out. 2019a. Disponível em: <http://www.christianunity.va/content/unitacristiani/it/news/notizie2019/2019-10-06-27-sinodo-per-l-amazzonia.html>. Acesso em: 31 out. 2019.

COSTA, M. C. C. O Aggiornamento do Pentecostalismo Brasileiro: as Assembleias de Deus e o processo de acomodação à sociedade de consumidores. São Paulo: Recriar, 2019b.

COSTA, M. C. C. Presentation of Pr. Moab César Carvalho Costa, Igreja Evangélica Assembleia de Deus no Brasil. 2019c. Disponível em: $<$ http://www.christianunity.va/content/unitacristiani/en/dialoghi/sezioneoccidentale/pentecostali/other-documents-and-events/intervention-du-pr-moab-cesarcarvalho-costa--assemblees-de-dieuo.html>. Acesso em: 31 out. 2019.

DE CERTEAU, M. La fábula mística (Siglos XVI-XVII). Madri: Siruela, 2006.

DE CERTEAU, M. A escrita da História. Tradução de Maria de Lourdes Menezes. 3. ed. Rio de Janeiro: Forense, 2011.

FRANCISCO. Encíclica Laudato Si'. Vaticano, 24 maio 2015.

PONTIFICAL COUNCIL FOR PROMOTING CHRISTIAN UNITY [PCPCU]. Delegati fraterni al Sinodo Pan-Amazzonico I News 2019. Disponível em: http://www.christianunity.va/content/unitacristiani/it/news/notizie-2019/2019-10-06-27sinodo-per-l-amazzonia.html. Acesso em: 31 out. 2019.

SECRETARIA GERAL DO SíNODO. Regulamento. Cidade do Vaticano: EPV, 2019.

RELATORIO CIRCOLO PORTOGHESE "A”. Cidade do Vaticano: Ed. Segreteria Generale del Sinodo, 2019. 